\title{
Andrej Kristan, Derecho y otros enigmas
}

(2017) Marcial Pons.

Madrid, 106 pp.

\author{
José Alejandro Fernández Cuesta \\ Universidad Complutense de Madrid (España) \\ ORCID ID 0000-0002-9637-9291 \\ josealef@ucm.es
}

Cita recomendada:

Fernández Cuesta, J. A. (2019). Andrej Kristan, Derecho y otros enigmas. Eunomía. Revista en Cultura de la Legalidad, 17, 404-407.

doi: https://doi.org/10.20318/eunomia.2019.5045

La obra comienza con una declaración de intenciones respecto de los dos objetivos que se pretenden alcanzar en ella: en primer lugar, se busca llevar a cabo una introducción a la Teoría del Derecho a aquellos lectores legos en la materia -como bien pudieran ser estudiantes de primeros cursos o juristas ejercientes ajenos al debate teórico-filosófico de las cuestiones planteadas-, en segundo lugar, el libro trata de realizar tal introducción aportando cierta originalidad orientada a la comunidad teórica en aras de la realización de un avance en lo que a la resolución de las propias problemáticas planteadas se refiere.

Siendo ésta la doble motivación material del presente volumen, cabe destacar su doble estructuración formal. Nos encontramos ante diez «enigmas» o problemas filosóficos del derecho divididos en dos bloques: los primeros cinco se agrupan bajo la rúbrica «enigmas filosóficos en la teoría del derecho» y los cinco últimos bajo el título «enigmas prácticos de la teoría del derecho». El desarrollo de los capítulos, planteados en términos lógico-filosóficos, pasará por, algunas veces, ofrecer soluciones a tales problemas, mientras que otros concluirán con la mera consideración del enigma en cuestión como relevante y, por tanto, digno de consideración por parte de la comunidad científica, que si bien no es propiamente una solución, tal consideración constituye, al menos, un cierto avance -o, como mínimo, la apertura de un debate-. Puesto que la limitación espacial impide un análisis detallado de cada uno de los diez capítulos, ofrecemos aquí una panorámica general del primer bloque mencionando brevemente los temas tratados en los cinco 
primeros capítulos que complementamos con un análisis más profundo del capítulo principal del segundo bloque.

«El jardín de Borges y lecturas "escribibles"» es el primero de los enigmas. En él se exponen ciertas tesis de la teoría literaria y se estudia su utilidad respecto del análisis teórico de los textos de naturaleza jurídica. Los códigos jurídicos y en general, los textos de naturaleza jurídica de carácter normativo -más allá de las sentencias jurisprudenciales o los manuales y artículos científicos doctrinales- revisten formalmente una estructuración peculiar por cuanto usualmente están divididos en artículos organizados en títulos, apartados, etc., lo que permite, precisamente, que sean leídos de formas muy diversas. Las teorías literarias acerca de los «hipertextos» y la distinción entre «textos legibles» y "textos escribibles» ilustran aquí la necesidad de una redefinición explicativa de la relación entre el legislador y el intérprete de las propias normas jurídicas. Las fuentes del derecho se analizan aquí, no ya como un simple texto, sino como algo "hipertextual», es decir, como una forma de escritura no secuencial que implica, por un lado, la existencia de «bloques de información» y, por otra, "vínculos de referencia cruzada» entre dichos bloques. Se busca explicitar la necesidad de analizar la composición formal de los textos jurídico-normativos desde una óptica diferente por la cual se igualan autor y legislador y no se desarrolla tal problemática.

«La identidad de lo variable» es el segundo capítulo. Aquí se pretende resolver, por medio de la aplicación de la teoría clásica de conjuntos, la aparente paradoja que implica la conjunción de, por un lado, la perpetuación de la identidad del derecho de un país $y$, por otro, los constantes y continuos cambios de las componentes de éste.

El tercer capítulo lleva por título «La paradoja de Hart» y hace referencia a una paradoja argumentativa que se estaría generando en la teoría hartiana de análisis de la problemática de la falibilidad de las decisiones judiciales definitivas. La paradoja sería la siguiente: (i) existe una decisión definitiva jurídicamente incorrecta; (ii) tal resolución existe en un sistema en que es jurídicamente correcto cumplir decisiones definitivas. El autor trae a colación la famosa «paradoja del barbero» acuñada por Bertrand Russell para proponer varios métodos de resolución de paradojas argumentativas y tratar de solventar así la problemática anterior.

«Futuras contingencias» es el cuarto enigma. Partiendo del capítulo IX del libro De Interpretatione de Aristóteles se estructura el problema filosófico que supone la afirmación, en un tiempo presente, de una proposición cuyo valor de verdad no podrá determinarse hasta un momento futuro concreto. Dicho tipo de proposiciones son frecuentes en la práctica jurídica: mediante un amplio espectro de ejemplos se ofrecen las posibles soluciones a este problema en el ámbito del derecho por analogía al trato que la problemática misma ha recibido en la tradición filosófica.

El enigma titulado «Desacuerdos sin error» cierra el primer bloque poniendo el foco de atención sobre los desacuerdos jurisprudenciales utilizando, para tal estudio, teorías de la filosofía del lenguaje, así como un gran número de ejemplos encuadrados en diversos sistemas jurídicos.

Respecto del segundo bloque, compuesto por los últimos cinco capítulos del libro, tal vez quepa detenerse un poco más en el titulado «Metarreglas de preferencia». Expondremos con mayor detalle la primera parte de este capítulo para ejemplificar el proceder del autor en la resolución de los enigmas planteados a lo largo de todo el libro. 
A partir de la teoría de conjuntos clásica y, por tanto, de una lógica de segundo orden -ya introducida en capítulos anteriores- se formalizan aquí las llamadas «metarreglas de preferencia», que no son otra cosa más que los tres criterios utilizados en la práctica jurídica a modo de resolución de conflictos normativos por concurrencia de normativa aplicable. Se trata de los criterios de jerarquía, especialidad y posterioridad en el tiempo. El autor los llama «metarreglas» por tratarse de reglas que, en última instancia, hacen mención al uso de otras reglas de carácter normativo. Siguiendo a Weinberger, este capítulo se plantea la cuestión de cómo representar el contenido proposicional de tales metarreglas sin dotar de contenido semántico al indicador de la fuerza elocutiva de las reglas objeto -lo que supondría abandonar la concepción pragmática de la norma en cuestión-. La solución a este problema técnico de representación pasará por representar el contenido proposicional (a) de la metarregla en cuestión operando sobre conjuntos que contengan, precisamente, los contenidos proposicionales de las reglas objeto y no, por el contrario, operando directamente sobre éstas.

Así se definen cuatro conjuntos $\mathbf{A}_{\mathbf{n}}$-como conjunto-ordenado-, $\mathbf{P}_{\mathbf{n}}$-como conjunto-permitido-, $\mathbf{D}_{\mathbf{n}}$-como conjunto-derogador, al cual se le dedica todo el capítulo anterior- y $\mathbf{C}_{n}\left(\mathbf{A}_{n}\right)$-como sistema normativo-. Se estipula, además, que el cambio de contenido de un conjunto cualquiera genera nuevos conjuntos así como que en un transcurso de tiempo concreto no se pueden tratar los cuatro conjuntos sino, por el contrario, cuatro secuencias. $Y$ se acota, por tanto, en base a las dos últimas reglas que: $\left[A_{1}, A_{2}, \ldots, A_{n} ; P_{1}, P_{2}, \ldots, P_{n} ; D_{1}, D_{2}, \ldots, D_{n} ; \ldots\right]$.Analizamos aquí solamente el trato de la primera de las metarreglas -lex posterior priori derogat-a modo meramente ilustrativo del procedimiento antes mencionado

Se define $\mathbf{t}$ como el contenido proposicional de la metarregla de preferencia cronológica. Se define, además, el objetivo a alcanzar: representar en una conjunción de condicionales dicha regla a partir de lo estipulado en el párrafo anterior de forma que los conjuntos consecutivos no incluyan los contenidos proposicionales de las oraciones normativas previas de manera que se formule una contradicción con los más recientes. Por último, se explicita que la lex posterior (t) no es sino la conjunción de los cuatro condicionales $\left(t_{1}, \ldots, t_{4}\right)$.

Finalmente se lleva a cabo la formalización de los cuatro condicionales y se establece una definición lógica formal del proceso de derogación. Dichas formalizaciones resultan útiles para poder llevar a cabo, no solamente un trato lógico de las metarreglas de preferencia sino, en general, para poder desarrollar un análisis formal de su uso y utilización concluyendo en qué casos es pertinente su uso y en cuáles no. El integrar los tres criterios de jerarquía, especialidad y posterioridad en este discurso lógico-deductivo permite, además, llevar a cabo un uso de tales criterios procedimentalmente con una seguridad que elimina cualquier ambigüedad $\mathrm{O}$ vaguedad en cuanto a dicha aplicación. Así se constituye, al menos en un plano teórico, el primer paso para la construcción de una herramienta útil en la práctica.

Las formalizaciones lógico-matemáticas, si tienen algo particular que a menudo los lógicos olvidan es que operan con variables y proposiciones que, en último término siempre son indeterminadas -0 , al menos, pendientes de instanciación si no de determinación extensional-: están por un enunciado, pero por un enunciado cualquiera. Dar el siguiente paso, consistente en hacerse cargo de los últimos avances de la lógica para aplicarlos a enunciados materiales que cubran tales instanciaciones, es algo que, a lo sumo, estamos habituados a hallar en literatura matemática. Aquí el derecho y las herramientas lógico-matemáticas se unen para plantear soluciones a problemas frecuentes de la práctica jurídica desde una perspectiva formal deductiva -pero materializada a partir de la sustitución de las 
variables indeterminadas por proposiciones jurídico-normativas- en un volumen que, sin duda alguna, reabre debates en torno a cuestiones filosófico-jurídicas relevantes permitiendo, además, el acceso a aquellos que no tengan conocimientos profundos en el estudio de la filosofía del derecho, la teoría del derecho o el estudio del análisis doctrinal de los problemas planteados a los diez «enigmas» aquí desarrollados -con una claridad y sencillez sorprendentes dado el nivel de complejidad alcanzado sobre todo en los últimos capítulos-. 